\title{
CARACTERIZAÇÃO AGRONÔMICA E FENOLÓGICA DE GENÓTIPOS DE ARROZ IRRIGADO PARA DETERMINAÇÃO DE MISTURA VARIETAL
}

\section{AGRONOMIC AND PHENOLIC CHARACTERIZATION OF IRRIGATED RICE GENOTYPES TO DETERMINE VARIETY MIXTURE}

\author{
Jaíza Francisca Ribeiro Chagas ${ }^{1}$; Matheus Vinicius Abadia Ventura ${ }^{2}$, Gil Rodrigues dos Santos ${ }^{3}$ \\ ${ }^{1}$ Doutorado em Produção Vegetal na Universidade Federal do Tocantins - Campus Gurupi. Universidade Federal do \\ Tocantins - jafraribeiro@gmail.com \\ 2 Mestrando em Ciências Agrárias - Instituto Federal Goiano - matheusvinicius10@hotmail.com. \\ ${ }_{3}^{3}$ Professor adjunto na Universidade Federal do Tocantins - Campus Gurupi. Universidade Federal do Tocantins - \\ gilrsan@uft.edu.br
}

\begin{abstract}
Resumo: Este trabalho objetivou identificar genótipos semelhantes quanto à características agronômicas e fenológicas para a formação de uma mistura varietal. O experimento foi realizado no campus de Gurupi, Universidade Federal do Tocantins. O delineamento utilizado foi o inteiramente casualizado (DIC) com três repetições. Os tratamentos consistiram de 37 genótipos de arroz irrigado. As características avaliadas foram germinação, floração, altura da planta, peso das panículas, comprimento das panículas, peso de 100 grãos, forma do grão, classe do grão, presença da arista e cor das glumelas. Os resultados foram submetidos à análise de variância e as médias avaliadas pelo teste de agrupamento de Scott-Knott, ao nível de $5 \%$ de probabilidade e análise multivariada. Evidenciou-se diferença significativa para a maioria das características estudadas, indicando variabilidade entre os genótipos. O genótipo Irri 344 chegou a floração aos 74 dias após o plantio, seguido dos cultivares Javaé e Irga 417 com 79 dias. O genótipo Eloni e o Mutante Multiespigueta da Embrapa foram os que apresentaram o ciclo mais tardio. Os genótipos com maior altura foram: Tetep com 131,3 cm e o Basmati com 128,3 cm. Para a classe do grão a maioria dos genótipos foi classificada como longo fino. $\mathrm{Na}$ análise multivariada houve a formação de 7 grupos. A floração foi à característica que mais influenciou na determinação dos grupos, exceto para o grupo 1 composto pelos genótipos Tetep e Basmati, que se distanciaram também em relação à altura. Os genótipos CNAI 5287, CNAI 9930 e Irri 344 não foram incluídos em nenhuma dos grupos, sendo a característica classe de grãos que determinou a maior dissimilaridade em relação aos demais grupos.

Palavras-chave: Oryza sativa, descritores morfológicos, brusone, mistura de cultivares.
\end{abstract}

\begin{abstract}
This work's objective was to identity similar genotypes within agronomic and phenolic characteristics to form a variety mixture. The experiment was performed at Federal University of Tocantins at Gurupi (Universidade Federal do Tocantins, Gurupi). The factorial scheme used was entirely random (DIC - Delineamento inteiramente casualizado), with three repetitions. The experiments consisted of 37 irrigated rice genotypes. The evaluated characteristics were: germination, flowering, plant eight, panicle weight, panicle length, 100 grain weight, grain form, grain class, arista presence, and husk color. The results were submitted to variance analysis and the averages were evaluated by Scott-Knott grouping test at $5 \%$ probability and multivariety analysis. There was evidence of considerable difference on the majority of studied characteristics, thus indicating variety among genotypes. Genotype Irri 344 reached flowering at 74 days after sowing, followed by genotypes Javaé and Irga 417 with 79 days. The genotype Eloni, and Mutante were in the latest cycle. The tallest genotypes were: Tetep with $131.3 \mathrm{~cm}$ (51.7 inches); and Basmati 128,3 (50.5 inches) The majority of genotypes were classified as long-fine. On the multivariety analysis, seven groups were arranged. Flowering was the most influencing characteristic in grain determination, except for group one (1) which was composed by Tetep and Basmati genotypes, which were also separated by eight. Genotypes CNAI 5287, CNAI 9930 and Irri 344 were not included in any group, because their grain characteristics displayed higher dissimilarity in relationship to the other groups.
\end{abstract}

Key-words: Oryza sativa, morphologic describers, rice blast, genotype mixture. 


\section{INTRODUÇÃO}

Dentre as culturas de importância social e econômica no Brasil, o arroz ocupa lugar de destaque, representando de 15 a 20\% do total de grãos colhidos no país (AZAMBUJA et al., 2004). O aumento crescente de seu consumo impõe aos setores produtivos a busca de novas técnicas que possam aumentar a produção. Cultivado e consumido em todos os continentes, o arroz destaca-se pela produção e área de cultivo, desempenhando papel estratégico tanto no aspecto econômico quanto social (EMBRAPA, 2005). Atualmente está entre as culturas mais plantadas e consumidas, sendo considerada a base da alimentação da maior parte da população mundial (VAUGHAN et al., 2005).

Um dos graves problemas para a manutenção da produtividade do arroz está na suscetibilidade dos genótipos atualmente em uso à doença brusone, causada pelo fungo Magnaporthe oryzae.

Atualmente, novas técnicas estão sendo estudadas para que haja redução da doença, entre elas o uso de mistura varietal. De acordo com Zhu et al. (2000), o uso da mistura varietal ou variedades compostas poderá ser uma das estratégias utilizadas para a obtenção de resistência estável à brusone. Consiste no plantio de uma mistura de sementes de duas ou mais cultivares com características agronômicas compatível, principalmente para o ciclo, altura de plantas e arquitetura da planta, mas cada uma portando um alelo diferente que condiciona resistência a uma determinada raça do patógeno prevalecente na região. Observações feitas demonstram que a heterogeneidade genética pode reduzir satisfatoriamente a ocorrência de doenças em grandes áreas de cultivo.

A mistura varietal é mais rápida e mais barata para se formular e modificar do que as multilinhas, que são definidas como mistura de linhas geneticamente e fenotipicamente uniformes de uma mesma espécie, que diferem apenas no nível de resistência para a doença (CASTRO, 2001).

Quando a mistura varietal é destinada à agricultura mecanizada, algum grau de uniformidade fenotípica é desejado, para facilitar as práticas de colheita. No entanto, quando é para a agricultura de subsistência os genótipos poderiam ser fenotipicamente diferentes, já que o pequeno produtor geralmente realiza a sua colheita manualmente.

Segundo Zhu et al. (2005), a utilização de genótipos com fenótipos diferentes ajuda a circulação do ar, a penetração mais direta da luz solar, reduzindo então a umidade das panículas dos materiais suscetíveis e como consequência à redução dos níveis de severidade da brusone das panículas.

No Tocantins, há uma rápida quebra da resistência dos genótipos lançados, isso ocorre devido à grande quantidade de raças existentes, fazendo com que, medidas de controle tradicionais como o uso do controle químico se torne ineficaz.

Considerando a importância econômica do arroz no Estado do Tocantins e a dificuldade de manter o controle da brusone nas lavouras de arroz, objetivou-se agrupar genótipos semelhantes quanto à característica agronômica e fenológica para a formação de mistura varietal. 


\section{MATERIAL E MÉTODOS}

O experimento foi conduzido em casa de vegetação no Campus de Gurupi, na Universidade Federal do Tocantins, no período compreendido entre janeiro a maio de 2009. O plantio das sementes foi feito em vaso com capacidade para cinco litros de substrato. O substrato utilizado foi uma mistura do substrato comercial PLANTMAX, solo, terra preta e esterco bovino numa proporção 1:1:1:1. A adubação foi de $50 \mathrm{~g}$ por vaso de NPK da fórmula 5-25-15. O delineamento experimental utilizado foi o inteiramente ao acaso (DIC) com três repetições, sendo semeadas 12 sementes por vaso.

Foram utilizados os genótipos comerciais de arroz irrigado Mutante; BRS Formoso; BRS Diamante; CNA 8502; Javaé; Metica 1; BRS Alvorada; BRS Guará; BRS Jaçanã, BRS Fronteira; BRS Ouro Minas; BRS Jaburu; BRS Biguá; BRS Taim; BRS Pelotas; CNAI 9930; Epagri 109; Irga 409; Irga 417; Cica 8; Bg 90-2; Ir 36; Irri 344; Oryzica 1; Oryzica Lhanos 4; Oryzica Lhanos 5; BRS Colômbia; Basmati; Eloni; Ir 34; Tetep; Cica 7; Cica 9; Epagri 114; Best; CNAI 9022 e CNAI 5287. A irrigação foi feita manualmente, durante todo o ciclo da cultura de modo a deixar uma lâmina constante de água. A colheita foi realizada manualmente, cortando-se as panículas abaixo do nó do pescoço e acondicionando-as em saquinhos de papel. A secagem das sementes foi realizada ao sol.

As características foram descritas de acordo com os descritores mínimos estabelecidos pelo SNPC (Sistema Nacional de Proteção a Cultivar) do Ministério da Agricultura, Pecuária e Abastecimento (MAPA) (BRASIL, 1997) e indicados pelo International Rice Institute (1980), com inclusões e alterações segundo Fonseca et al. (2004). As características avaliadas foram: Germinação das sementes: (dias transcorridos da semeadura até a emissão da plântula); Altura de plantas (distância em centímetros medida da superfície do solo até a extremidade da folha mais alta); Floração: (dias transcorridos da germinação até a emissão de 50\% de panículas); Peso de panículas (peso em gramas de 5 panículas); Comprimento de panículas: (distância em centímetros da base da panícula até a ponta da última espigueta, classificada em 1 - pequena $(<22$ $\mathrm{cm})$, média (entre 22 e $26 \mathrm{~cm}$ ) e grande $(>26 \mathrm{~cm}$ ); Peso de 100 grãos em g; Forma do grão: classificado com base na relação comprimento/ largura: 1 - arredondada (C/L menor que 1,5); 2 semi arrendodada (C/L entre 1,5 e 2); 3 - meio alongada (C/L entre 2,01 e 2,75); 4 - alongada (C/L entre 2,76 e 3,5); 5 - muito alongada (C/L maior que 3,5); Classe do grão: 1 - longo - fino (comprimento maior ou igual a $6 \mathrm{~mm}$, espessura menor ou igual a $1,9 \mathrm{~mm}$ e $\mathrm{C} / 1$ maior ou igual a 2,75 mm); 2 - longo (comprimento maior ou igual a $6 \mathrm{~mm}$ ); 3 - médio (comprimento entre 5 e $6 \mathrm{~mm}$ ) e 4 - curto (comprimento menor que $5 \mathrm{~mm}$ ); Presença da arista: (classificada em 1 ausente/muito curta; 2 - curta; 3 - média; 4 - longa e 5 - muito longa) e - Cor das glumelas: (determinada mediante escala: 1 - amarelo-palha; 2 - dourada; 3 - manchas-marrons; 4 - estriasmarrons; 5 - marrom; 6 - avermelhada; 7 - manchas púrpuras; 8 - estrias púrpuras; 9 - púrpura; 10 preta.

Os dados foram submetidos à análise de variância e as médias submetidas ao teste de Scott- 
Knott ao nível de $5 \%$ de probabilidade. Para os dados de altura de plantas, floração e classe de grão foi aplicado a análise de componentes principais e o método de agrupamento hierárquico utilizando a distância generalizada de Mahalanobis com o auxílio do software MATLab 7,0.

\section{RESULTADOS E DISCUSSÃO}

De acordo com a análise estatística foi evidenciada diferença significativa para a maioria das características estudadas, indicando variabilidade entre os genótipos (Tabela

1). Os genótipos BRS Formoso, Guará, BRS Ouro minas, BRS Biguá, CNAI 9930, Cica 7 e Cica 9 apresentaram a germinação mais rápida de 2 dias, enquanto o genótipo Eloni apresentou a germinação mais lenta com 7 dias. A variação na germinação de sementes de arroz pode ser influenciada pelas condições ambientais, profundidade na qual a semente foi depositada, bem como pela presença de fungos associados ou dormência que pode ser causada por colheita prematura dos grãos.

Nesta pesquisa destacam-se como os mais precoces o genótipo Irri 344 que atingiu a floração plena aos 74 dias após o plantio, seguido dos cultivares Javaé e Irga 417 com 79 dias. O genótipo Eloni e o Mutante foram os que apresentaram maior tempo para atingir o estádio de $50 \%$ de panículas de 100 dias, o que pode ser explicado pela germinação mais demorada no caso do genótipo Eloni. Acredita-se que, durante a condução do experimento, o ciclo dos genótipos foi acelerado, devido à alta temperatura durante o dia na casa de vegetação, além da alternância de períodos ensolarados e chuvosos, juntamente com o estresse causados nas raízes em decorrência do plantio ter sido realizado em vaso. A data de floração varia de uma região para outra, em função do fotoperíodo e da temperatura. Geralmente, estresses hídricos e nutricionais, afetam o ciclo natural das plantas (BRESEGHELLO et al., 1998).

Os genótipos com maior altura foram Tetep e Basmati com 131,3 cm e 128, 3 cm (Tabela 1), sendo que, quatro genótipos tiveram sua altura classificada como alta (entre 1,21 a 1,50 m) e 26 genótipos tem altura média (entre 1,00 à 1,20 m). Costa et al. (2000), encontraram valores inferiores de altura para os genótipos Irga 409 (89 cm), Javaé $(57 \mathrm{~cm})$, Metica $1(80 \mathrm{~cm})$ e Diamante $(76 \mathrm{~cm})$ quando comparados com os resultados deste trabalho. Fonseca et al. (2006), avaliando a altura do genótipo BRS Fronteira encontraram valores de 106,9 cm. Para o comprimento de panículas encontrou valores entre 22,5 a $26,5 \mathrm{~cm}$ e arista que os autores denominaram de micro-arista e cor das glumelas amarelo-palha, próximos aos encontrados neste trabalho para este genótipo. Segundo Fonseca et al. (2002), a altura da planta é influenciada pelo ambiente e em determinadas circunstâncias pela quantidade de nitrogênio aplicado. As maiores alturas encontrados neste trabalho em comparação a outros pode estar relacionado ao fato dos genótipos terem sido plantados em substrato composto com alto nível de matéria orgânica, pela presença de esterco bovino, terra preta e substrato comercial PLANTMAX, o que melhora a qualidade do solo e disponibilidade de nutrientes para as plantas.

Para o formato do grão, 30 genótipos foram classificados como alongados, quatro genótipos como meio alongado e 3 genótipos 
como muito alongado. Quanto à classe do grão, 34 genótipos foram classificados em longo fino, dois em grão longo e um como médio. A similaridade da maioria dos genótipos para estas características é benéfica, pois cumpre um dos requisitos básico para se compor uma mistura de cultivares (Tabela 1).

Quanto à presença da arista, um segmento filamentoso que ocorre no ápice do grão, 24 genótipos apresentaram classificação 1, sendo ausente ou muito curta, 13 genótipos apresentaram aristas que variaram de curta a muito longa (Tabela 1). No caso da arista, apesar de ser um caráter monogênico de alta herdabilidade, pode ter o comprimento alterado pelas condições ambientais, principalmente pela fertilidade do solo e densidade de plantio utilizada (FONSECA et al., 2004).

O genótipo Colômbia foi o que apresentou a menor massa dos grãos de $1,75 \mathrm{~g}$, os maiores valores variaram de 3,15 a 3,19 g (Tabela 1). Costa et al. (2000) encontraram valores de 2,59 g; 2,19 g e 2,07 g para os cultivares IRGA 409, Metica 1 e Diamante. O genótipo Colômbia e o Ir 34 apresentaram cor das glumelas diferentes dos demais genótipos sendo dourado e presenças de manchas marrons.

Em estudos de caracterização fenológica de genótipos de arroz irrigado: BRS Biguá, BRS Jaburu, BRS Formoso, BRS Ouro minas, Javaé, Metica 1 e Diamante, Fonseca et al. (2002), encontraram maiores valores para a floração, em geral menores valores para ltura de plantas, valores próximos para o comprimento de panículas e as mesmas considerações sobre a arista, quando comparado com este trabalho. Dentre os cultivares recomendados para plantio nas condições do estado do Tocantins estão BRS Alvorada, BRS Biguá, BRS Formoso, BRS Jaburu, Javaé e Metica 1 (MORAIS et al., 2006), principalmente devido a excelente produtividade.

De acordo com o dendrograma (Figura 1), observou-se a formação de sete grupos. O ciclo ou floração foi à característica que mais influenciou na definição dos grupos, exceto para o primeiro grupo que foi influenciado também pela altura. A classe dos grãos é igual para 34 genótipos, exceto para os genótipos CNAI 5287, CNAI 9930 e Irri 344. De cima para baixo o grupo 1 foi formado pelos genótipos Tetep e Basmati, se diferenciou dos demais devido os genótipos apresentarem as maiores alturas e floração semelhante. O grupo 2 foi formado pelos genótipos Oryzica Lhanos 5, Ir 34, Epagri 109, Epagri 114, Metica-1 e Oryzica 1 com a floração entre 92 - 93 dias. O grupo 3 foi formado pelos genótipos BRS Javaé e Irga 417 com floração de 79 dias e CNA 8502 e Pelotas com floração de 81 dias.

O grupo 4 foi formado pelos genótipos BRS Guará e Cica 8. O grupo 5 foi formado pelos genótipos Best, CNAI 9022, BRS Fronteira, Cica, Irga 409, Cica 9, BRS Formoso e BRS Jaçanã. Este grupo apresenta os genótipos com dados de alturas intermediários dentre os demais grupos, no entanto a floração está abaixo da média, sendo que os genótipos BRS Fronteira e Cica 7 foram os que tiveram a menor dissimilaridade. $O$ grupo 6 formado pelos genótipos Ouro minas, Bg-90-2, BRS Jaburu, Oryzica Lhanos 4, BRS Alvorada, BRS Diamante e Taim. Este grupo apresenta os genótipos com alturas um pouco superiores a média geral de todos os genótipos, no entanto a 
floração apresenta valores intermediários em

relação aos demais genótipos.

Tabela 1 - Valores de Germinação (G), Floração (FLO), Altura da planta em cm (ALT), Peso de panículas em g (PP), Comprimento de panículas em $\mathrm{cm}(\mathrm{CP})$, Formato do grão (FG), Arista (Ari), Peso de 100 grãos em g (P100G), Classe de grão $\left(\mathrm{CG}^{1}\right)$ e Cor das glumelas $\left(\mathrm{CG}^{2}\right)$ de genótipos de arroz em Gurupi - TO em 2009

$\begin{array}{llllllllll}\text { GENÓTIPOS } & \text { G } & \text { FLO } & \text { ALT } & \text { PP } & \text { CP } & \text { FG* }^{*} \text { CG }^{1} & \text { Ari* } & \text { P100G } & \text { CG }^{2}\end{array}$

\begin{tabular}{|c|c|c|c|c|c|c|c|c|c|c|}
\hline 1- Mutante & $4,66 \mathrm{a}$ & $100,0 \mathrm{a}$ & $96,16 \mathrm{~d}$ & $13,41 \mathrm{~b}$ & $21,13 \mathrm{~b}$ & 4 & 1 & 1 & $2,79 \mathrm{c}$ & 1 \\
\hline 2- BRS Formoso & $2,00 \mathrm{~b}$ & $83,66 \mathrm{~b}$ & $101,3 \mathrm{~d}$ & $13,43 \mathrm{~b}$ & $24,31 \mathrm{a}$ & 4 & 1 & 1 & $2,86 \mathrm{c}$ & 1 \\
\hline 3- Diamante & $3,33 \mathrm{~b}$ & $87,00 \mathrm{~b}$ & $99,50 \mathrm{~d}$ & $11,83 \mathrm{~b}$ & $21,09 \mathrm{~b}$ & 4 & 1 & 1 & $2,78 \mathrm{c}$ & 1 \\
\hline 4- CNA 8502 & $4,66 \mathrm{a}$ & $81,00 \mathrm{~b}$ & $104,3 \mathrm{c}$ & $12,46 \mathrm{~b}$ & $21,96 \mathrm{~b}$ & 4 & 1 & 1 & $2,60 \mathrm{~d}$ & 1 \\
\hline 5- Javaé & $6,00 \mathrm{a}$ & $79,66 \mathrm{~b}$ & $104,5 \mathrm{c}$ & $8,50 \mathrm{~b}$ & $20,43 \mathrm{~b}$ & 4 & 1 & 1 & $2,56 \mathrm{~d}$ & 1 \\
\hline 6- Metica 1 & $6,00 \mathrm{a}$ & $92,33 \mathrm{a}$ & $95,16 \mathrm{~d}$ & $13,36 \mathrm{~b}$ & $21,13 \mathrm{~b}$ & 4 & 1 & 5 & $2,68 \mathrm{c}$ & 1 \\
\hline 7- BRS Alvorada & $3,33 \mathrm{~b}$ & $89,00 \mathrm{~b}$ & $106,1 \mathrm{c}$ & $12,97 \mathrm{~b}$ & $22,00 \mathrm{~b}$ & 4 & 1 & 5 & $2,82 \mathrm{c}$ & 1 \\
\hline 8- BRS Guará & $2,00 \mathrm{~b}$ & 91,33 a & $114,3 \mathrm{~b}$ & $21,38 \mathrm{a}$ & $23,20 \mathrm{a}$ & 4 & 1 & 1 & $2,85 \mathrm{c}$ & 1 \\
\hline 9- BRS Jaçanã & $4,66 \mathrm{a}$ & $84,33 \mathrm{~b}$ & $100,1 \mathrm{~d}$ & $13,11 \mathrm{~b}$ & $22,30 \mathrm{~b}$ & 4 & 1 & 1 & $2,74 \mathrm{c}$ & 1 \\
\hline 10- BRS Fronteira & $5,33 \mathrm{a}$ & $85,33 \mathrm{~b}$ & $109,3 \mathrm{c}$ & $16,06 \mathrm{a}$ & $24,12 \mathrm{~b}$ & 4 & 1 & 1 & $2,83 \mathrm{c}$ & 1 \\
\hline 11- Ouro minas & $2,00 \mathrm{~b}$ & $88,00 \mathrm{~b}$ & $107,8 \mathrm{c}$ & $13,20 \mathrm{~b}$ & $23,35 \mathrm{a}$ & 4 & 1 & 1 & $3,03 \mathrm{~b}$ & 1 \\
\hline 12- BRS Jaburu & $6,00 \mathrm{a}$ & $88,66 \mathrm{~b}$ & $111,3 \mathrm{~b}$ & $15,84 \mathrm{a}$ & $26,28 \mathrm{a}$ & 4 & 1 & 4 & $2,88 \mathrm{c}$ & 1 \\
\hline 13- BRS Biguá & $2,00 \mathrm{~b}$ & $88,66 \mathrm{~b}$ & $124,6 \mathrm{a}$ & $15,06 \mathrm{a}$ & $24,07 \mathrm{a}$ & 4 & 1 & 1 & $2,80 \mathrm{c}$ & 1 \\
\hline 14- BRS Taim & $4,66 \mathrm{a}$ & $83,00 \mathrm{~b}$ & $112,5 \mathrm{~b}$ & $16,51 \mathrm{a}$ & $21,68 \mathrm{~b}$ & 4 & 1 & 1 & $2,58 \mathrm{~d}$ & 1 \\
\hline 15- BRS Pelotas & $3,33 \mathrm{~b}$ & $81,66 \mathrm{~b}$ & $106,3 \mathrm{c}$ & $13,35 \mathrm{~b}$ & $24,94 \mathrm{a}$ & 5 & 1 & 2 & $2,67 \mathrm{c}$ & 1 \\
\hline 16- CNAI 9930 & $2,00 \mathrm{~b}$ & $88,66 \mathrm{~b}$ & $101,1 \mathrm{~d}$ & $16,74 \mathrm{a}$ & $24,21 \mathrm{a}$ & 3 & 2 & 3 & $3,19 \mathrm{a}$ & 1 \\
\hline 17- Epagri 109 & $5,33 \mathrm{a}$ & $92,66 \mathrm{a}$ & $103,6 \mathrm{c}$ & $15,02 \mathrm{a}$ & $23,07 \mathrm{a}$ & 4 & 1 & 1 & $2,91 \mathrm{c}$ & 1 \\
\hline 18- Irga 409 & $3,33 \mathrm{~b}$ & $84,33 \mathrm{~b}$ & $108,5 \mathrm{c}$ & $14,37 \mathrm{a}$ & $23,74 \mathrm{a}$ & 4 & 1 & 2 & $2,75 \mathrm{c}$ & 1 \\
\hline 19- Irga 417 & $6,00 \mathrm{a}$ & $79,00 \mathrm{~b}$ & $101,6 \mathrm{~d}$ & $12,30 \mathrm{~b}$ & $22,20 \mathrm{~b}$ & 5 & 1 & 2 & $2,63 \mathrm{~d}$ & 1 \\
\hline 20- Cica 8 & $5,33 \mathrm{a}$ & 90,66 a & $113,0 \mathrm{~b}$ & $17,34 \mathrm{a}$ & $22,53 \mathrm{a}$ & 4 & 1 & 1 & $2,52 \mathrm{~d}$ & 1 \\
\hline 21- Bg 90-2 & $5,33 \mathrm{a}$ & $88,00 \mathrm{~b}$ & $109,8 \mathrm{c}$ & 17,16 a & 22,83 a & 4 & 1 & 1 & $3,15 \mathrm{a}$ & 1 \\
\hline $22-$ Ir 36 & $4,66 \mathrm{a}$ & $80,66 \mathrm{~b}$ & $91,50 \mathrm{~d}$ & $11,52 \mathrm{~b}$ & $18,78 \mathrm{c}$ & 4 & 1 & 1 & $2,31 \mathrm{e}$ & 1 \\
\hline 23- Irri 344 & $3,33 \mathrm{~b}$ & $74,00 \mathrm{~b}$ & $105,7 \mathrm{c}$ & $14,10 \mathrm{~b}$ & $18,91 \mathrm{c}$ & 3 & 3 & 1 & $2,63 \mathrm{~d}$ & 1 \\
\hline 24- Oryzica 1 & $4,00 \mathrm{~b}$ & 90,33 a & $96,60 \mathrm{~d}$ & $12,92 \mathrm{~b}$ & $16,69 \mathrm{c}$ & 5 & 1 & 1 & $2,87 \mathrm{c}$ & 1 \\
\hline $\begin{array}{l}\text { 25- Oryzica } \\
\text { Lhanos } 4\end{array}$ & $4,00 \mathrm{~b}$ & $87,66 \mathrm{~b}$ & $104,3 \mathrm{~d}$ & $13,29 \mathrm{~b}$ & $22,76 \mathrm{a}$ & 4 & 1 & 3 & $2,52 \mathrm{~d}$ & 1 \\
\hline $\begin{array}{lll}26 & - & \text { Oryzica } \\
\text { Lvanos } 5 & \end{array}$ & Oryzica 4,66 a & $93,66 \mathrm{a}$ & $101,1 \mathrm{~d}$ & $14,91 \mathrm{a}$ & $14,91 \mathrm{a}$ & 4 & 1 & 1 & $2,86 \mathrm{c}$ & 1 \\
\hline 27 - Columbia & 5,33 a & $96,00 \mathrm{a}$ & $113,6 \mathrm{~b}$ & $17,06 \mathrm{a}$ & $22,96 \mathrm{a}$ & 4 & 1 & 2 & $1,75 \mathrm{f}$ & 2 \\
\hline 28- Basmati & $6,00 \mathrm{a}$ & $96,00 \mathrm{a}$ & $128,3 \mathrm{a}$ & $9,68 \mathrm{~b}$ & $23,36 \mathrm{a}$ & 4 & 1 & 3, & $2,29 \mathrm{e}$ & 1 \\
\hline 29- Eloni & $7,66 \mathrm{a}$ & $100,0 \mathrm{a}$ & $94,50 \mathrm{~d}$ & $14,68 \mathrm{a}$ & $21,67 \mathrm{~b}$ & 4 & 1 & 1 & $2,82 \mathrm{c}$ & 1 \\
\hline $30-$ Ir 34 & $2,00 \mathrm{~b}$ & 93,66 a & $99,50 \mathrm{~d}$ & 14,86 a & $21,10 \mathrm{~b}$ & 4 & 1 & 1 & $2,45 \mathrm{e}$ & 3 \\
\hline 31- Tetep & $6,00 \mathrm{a}$ & 98,33 a & $131,3 \mathrm{a}$ & $7,84 \mathrm{~b}$ & $21,65 \mathrm{~b}$ & 3 & 1 & 1 & $2,25 \mathrm{e}$ & 1 \\
\hline 32- Cica 7 & $2,00 \mathrm{~b}$ & $85,00 \mathrm{~b}$ & $109,3 \mathrm{c}$ & $11,28 \mathrm{~b}$ & 23,13 a & 4 & 1 & 2 & $2,87 \mathrm{c}$ & 1 \\
\hline 33- Cica 9 & $2,00 \mathrm{~b}$ & $86,33 \mathrm{~b}$ & $113,0 \mathrm{~b}$ & $15,61 \mathrm{a}$ & $25,62 \mathrm{a}$ & 4 & 1 & 1 & $2,99 \mathrm{~b}$ & 1 \\
\hline 34- Epagri 114 & $3,33 \mathrm{~b}$ & $92,66 \mathrm{a}$ & $105,0 \mathrm{c}$ & $17,82 \mathrm{a}$ & $24,48 \mathrm{a}$ & 4 & 1 & 1 & $2,94 \mathrm{c}$ & 1 \\
\hline 35- Best & $2,66 \mathrm{~b}$ & $85,00 \mathrm{~b}$ & $105,6 \mathrm{c}$ & $17,74 \mathrm{a}$ & $23,08 \mathrm{a}$ & 4 & 1 & 3 & $2,53 \mathrm{~d}$ & 1 \\
\hline 36- CNAI 9022 & $2,66 \mathrm{~b}$ & $85,66 \mathrm{~b}$ & $103,1 \mathrm{c}$ & $13,45 \mathrm{~b}$ & $22,90 \mathrm{a}$ & 4 & 1 & 5 & $2,86 \mathrm{c}$ & 1 \\
\hline 37- CNAI 5287 & $4,00 \mathrm{~b}$ & $89,33 \mathrm{~b}$ & $120,2 \mathrm{~b}$ & $16,77 \mathrm{a}$ & $18,71 \mathrm{c}$ & 3 & 2 & 1 & $3,16 \mathrm{a}$ & 1 \\
\hline CV\% & 54,58 & 5,74 & 4,69 & 17,79 & 6,71 & & & & 3,40 & \\
\hline Média & 4,10 & 88,16 & 106,78 & 14,24 & 22,55 & & & & 2,72 & \\
\hline
\end{tabular}

O grupo 7 foi formado pelos genótipos Mutante e Eloni, apresentando dissimilaridade baixa, provavelmente o que definiu este grupo foi á floração mais tardia em relação aos demais 
genótipos. Ambos necessitaram de 100 dias para que emitissem $50 \%$ de panículas. Os genótipos Ir 36, Biguá, Colômbia, CNAI 5287, CNAI 9930 e Irri 344 não se inseriram em nenhum dos grupos. O genótipo Ir 36 teve uma floração baixa entre os demais genótipos, de 80 dias. O genótipo Biguá poderia integrar o grupo 6 , mas a altura de 124,6 $\mathrm{cm}$ não condiz com as alturas dos genótipos que compõem este grupo. O genótipo Colômbia não foi inserido no grupo 1 devido a sua altura.

Os genótipos CNAI 5287 e CNAI 9930 pertencem à classe de grão longo. Enquanto que a maior amplitude de diversidade genética entre o genótipo Irri 344 em relação aos demais foi exclusivamente por este material pertencer á classe de grão médio e ser o mais precoce em relação à floração com 74 dias. Estas características impedem que este genótipo possa constituir uma mistura de cultivares, onde as semelhanças para as características agronômicas são requeridas. Cargnin e Souza (2007), analisando a diversidade genética de 25 genótipos de arroz de terras altas por meio da análise multivariada obtiveram a formação de nove grupos baseado em características agronômicas

Dendrograma usando a distancia de Mahalanobs no $2 \mathrm{PCa}$

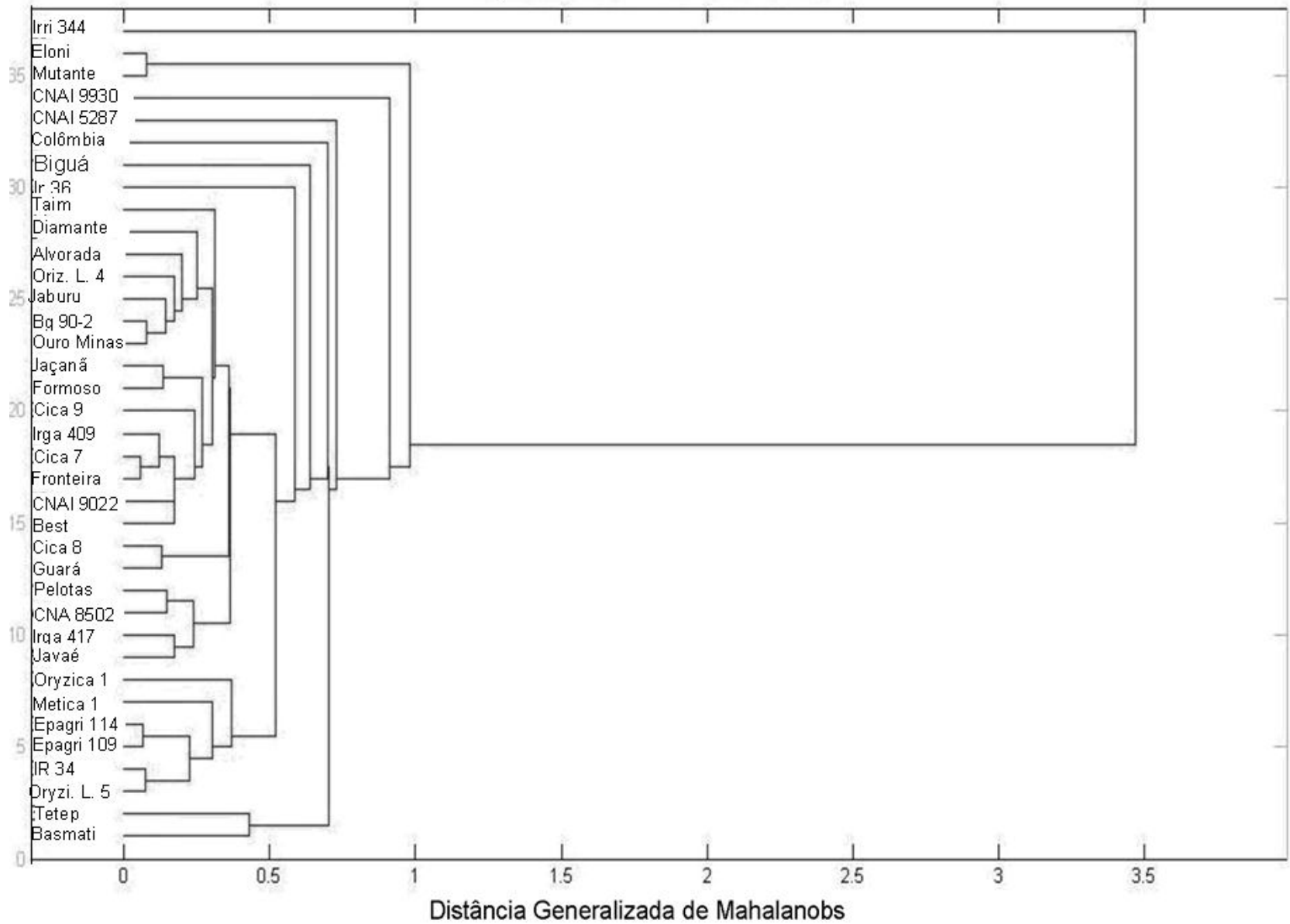

Figura 1 - Dendrograma representativo da dissimilaridade genética entre 37 genótipos de arroz irrigado, em Gurupi-TO, 2009, obtidos pela técnica do vizinho mais próximo, utilizando a distância generalizada de Mahalanobis como medida de dissimilaridade. 
A mistura varietal define-se basicamente em uma mistura de diferentes genótipos de arroz. Torna-se se necessário que os componentes de uma mistura sejam semelhantes para algumas características fenológicas, sendo as principais: altura da planta, floração e qualidade do grão (ZHU et al., 2000; CASTRO, 2001). Estes requisitos mínimos são necessários para uniformizar a lavoura e evitar diferenças muitos contrastantes na hora da maturação e a colheita, facilitando dessa forma o trabalho dos produtores, sejam eles de pequena tecnologia ou não.

A dispersão gráfica dos escores revelou que os genótipos mais distanciados em relação aos demais para a classe dos grãos foram os genótipos 23 (Irri 344), 37 (CNAI 5287) e o 16 (CNAI 9930), (Figura 2). Estes resultados concordam com os obtidos no dendrograma, portanto, confiáveis na identificação de grupos de genótipos de arroz, no sentido de orientar a formação de uma mistura de cultivares levando-se em consideração a altura, floração e classe de grãos. Vários trabalhos com análise de agrupamento foram realizados com intuito de verificar a diversidade genética em genótipos, tais como: Bertan et al. (2006), em trigo, Rodrigues et al. (2002) e Moreira et al. (2009), em feijão e Pelúzio et al. (2009), em soja.

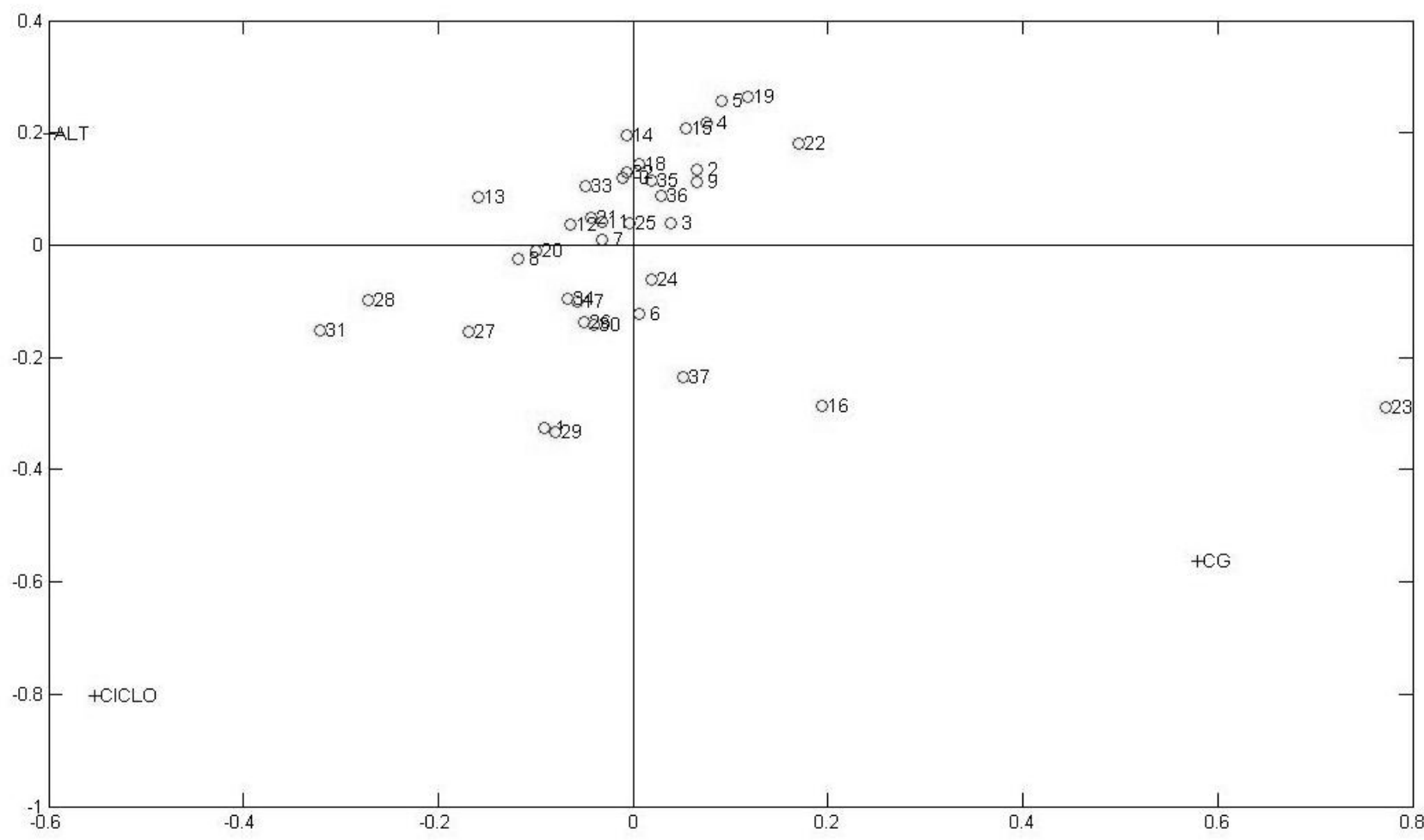

Figura 2- Dispersão gráfica dos escores de 37 genótipos de arroz, em relação às variáveis: classe do grão, floração e altura, 2009.

Genótipos: 1 - Mutante da Embrapa; 2 - BRS Formoso; 3 - Diamante; 4 - CNA 8502; 5 - Javaé; 6 - Metica 1; 7 BRS Alvorada; 8 - BRS Guará; 9 - BRS Jaçanã; 10 - BRS Fronteira; 11 - BRS Ouro minas; 12 - BRS Jaburu; 13 BRS Biguá; 14 - BRS Taim; 15 - BRS Pelotas; 16 - CNAI 9930; 17 - Epagri 109; 18 - Irga 409; 19 - Irga 417; 20 Cica 8; 21 - Bg 90-2; 22 - Ir 36; 23 - Irri 344; 24 - Oryzica 1; 25 - Oryzica Lyanos 4; 26 - Oryzica Lhanos 5; 27 Colômbia; 28 - Basmati; 29 - Eloni; 30 - Ir 34; 31 - Tetep; 32 - Cica 7; 33 - Cica 9; 34 - Epagri 114; 35 - Best; 36 CNAI 9022; 37 - CNA 5287. 
De acordo com os resultados obtidos da análise multivariada, pode-se inferir através dos grupos formados a composição de uma mistura varietal. Entretanto, para que o sucesso dessa mistura seja efetivo, é necessário testar os componentes escolhidos em diferentes proporções e combinações nas condições de campo, em vários locais e anos para que se observe a interação.

Como citado anteriormente, a escolha dos genótipos não deve ser baseada somente nas características agronômicas, mas, deve-se também levar em consideração a resposta de resistência diferencial dos genótipos às principais raças do fungo M. oryzae.

\section{CONCLUSÃO}

Os genótipos foram divergentes quanto aos caracteres altura de plantas e floração.

Houve a formação de sete grupos, sendo a floração a característica que mais influenciou na formação dos grupos.

Podem-se utilizar todos os componentes para compor uma mistura, desde que estes pertençam ao mesmo grupo. No entanto, é necessário que a escolha dos genótipos para compor a mistura de cultivares tenha além de características agronômicas semelhantes, resistência diferencial às raças do fungo $M$. oryzae.

\section{REFERÊNCIAS BIBLIOGRAFICAS}

AZAMBUJA, I. H. V.; VERNETTI JUNIOR, F. J.; MAGALHÃES JUNIOR, A. M. Aspectos socioeconômicos da produção de arroz. In: GOMES, A. S.; MAGALHÃES JÚNIOR, A. M. (Ed.). Arroz irrigado no sul do Brasil. Embrapa, Brasília. 2004. 23-44.
BERTAN, I.; CARVALHO, F. I. F.; OLIVEIRA, A. C.; SILVA, J. A. G.; et al. Dissimilaridade genética entre genótipos de trigo avaliados em cultivo hidropônico sob estresse por alumínio. Revista Bragantia. 2006; 65:55-63.

BRASIL. Decreto $n^{\circ} 2.366$, de 5 de novembro de 1997. Regulamenta a lei $n^{\circ} 9.456$, de 25

de abril de 1997, que institui a proteção de cultivares, dispõe sobre o Serviço Nacional de

Proteção de Cultivares - SNPC, e dá outras providências. Diário Oficial [da] República

Federativa do Brasil, Brasília, DF, 7. Seção 1, p. 25342-25343, nov. 1997.

BRESEGHELLO, F.; CASTRO, E. M.; MORAIS, O. P. Cultivares de arroz. In: BRESEGHELO, F.; STONE, L. F. (Ed.). Tecnologia para o arroz de terras altas. Santo Antônio de Goiás: Embrapa Arroz e Feijão. 1998. 41- 53.

\section{CARGNIN, A.; SOUZA, M. A. Diversidade} genética em cultivares de arroz. Planaltina: Distrito Federal. Embrapa Cerrados. 2007. (Documentos 196).

CASTRO, A. Cultivar Mixtures. The Plant Health Instructor. DOI: 10.1094/PHI-A-2001-123001.), 2001. [Acesso em: 15 nov 2009]. Disponível em: http://www.apsnet.org/Education/Advanced PlantPath/Topics/cultivarmixtures/what_is_p g1.htm.

COSTA, E. G. C.; SANTOS, A. B.; ZIMMERMANN, F. J. P. Características agronômicas da cultura principal e da Soca de arroz irrigado. Ciência Agrotécnica. 2000; 24:15-24 (Edição Especial).

EMBRAPA- Embrapa clima temperado. Cultivo de arroz irrigado no Brasil. Sistemas de produção, 3 ISSN 1806-9207 versão eletrônica. 2005. [acesso em: 08 agos 2008]. Disponível em: http:// www.cpact.embrapa.br/ sistemas/arroz/autores.htm.

FONSECA, J. R.; CUTRIM, V. A.; RANGEL, P. H. N. Descritores Morfo Agronômicos e Fenológicos de Cultivares Comerciais de Arroz de Várzeas. Santo Antônio de Goiás: Embrapa Arroz e Feijão. 2002. (Documentos, 141) 
FONSECA, J. R.; CASTRO, E. M.; MORAIS, O. P. Descritores morfo agronômicos e fenológicos de cultivares comerciais de arroz (Oryza sativa L.) de terras altas. Santo Antônio de Goiás:Embrapa Arroz e Feijão. 2004. (Documentos, 162)

FONSECA, J. R.; CASTRO, E. M.; MORAIS O. P. Características Botânicas, Agronômicas e Fenológicas de Cultivares de Arroz de Terras Altas. Santo Antônio de Goiás: Embrapa Arroz e Feijão. 2006. (Documentos, 120)

IRRI. Catalog of descriptors for rice (Oryza sativa L.). Manila: IRRI: IBPGR. 1980; 21.

MORAIS, O. P.; RANGEL, P. H. N.; FAGUNDES, P. R. R.; et al. Melhoramento genético. In: A cultura do arroz no Brasil $\left(2^{\circ}\right.$ ed.). EMBRAPA/CNPAF, Santo Antônio GO. 2006; 289-358.

MOREIRA, R. M. P.; FERREIRA, J. M.; TAKAHASHI, L. S. A.; et al. Potencial agronômico e divergência genética entre genótipos de feijão-vagem de crescimento determinado. Ciências Agrárias. 2009; 30: 1051-1060.

RODRIGUES, L. S.; ANTUNES, I. F.; TEIXEIRA, M. G.; et al. Divergência genética entre cultivares locais e cultivares melhoradas de feijão. Pesquisa Agropecuária Brasileira. 2002; 37: 1275-1284.

PELUZIO, J. M.; VAZ-DE-MELO, A.; AFFÉRRI, F. S.; et al. Variabilidade genética entre cultivares de soja, sob diferentes variações edafoclimaticas, na região centro-sul do estado do Tocantins. Pesquisa Aplicada e Agrotecnologia. 2009; 2:1.

VAUGHAN, D. A.; KADOWAKI, K.; KAGA, A.; et al. On the phylogeny and biogeography of the genus Oryza. Breeding Science. 2005; 55:113-122.

ZHU, Y.; CHEN, H.; FAN, J. WANG, Y.; et al. Genetic diversity and disease control in rice. Nature. 2000, 406:718-722.

ZHU, Y. Y.; FANG, H.; WANG, Y.Y.; et al. Panicle blast and canopy moisture in rice cultivar mixtures. Phytopathology. 2005; 95:433-438. 